\title{
Investigar y narrar el crimen en la Argentina. El periodismo narrativo y la crónica policial de Javier Sinay y Rodolfo Palacios
}

\author{
Francisco Jiménez Sánchez \\ fjsanchezgz@gmail.com
}

\begin{abstract}
María Angulo Egea
Universidad de Zaragoza. Periodismo. Facultad de Filosofía y Letras.

mangulo@unizar.es
\end{abstract}

Recibido: 20 de abril de 2017. Aceptado: 5 de septiembre de 2017.

\section{Resumen}

El crimen y el delito están presentes cotidianamente en los medios de comunicación. Sin embargo, el periodismo que trata estos temas no goza del prestigio que tienen otros géneros. El periodismo policial se encuentra a menudo en una encrucijada. El respeto a las víctimas, la ética o las normas deontológicas se enfrentan, en la cobertura mediática de hechos luctuosos, a la apelación al morbo, la espectacularización y el amarillismo.

El presente trabajo traza una evolución en ciertas formas de abordar el periodismo policial argentino que entendemos relevantes. Desde los nuevos modos planteados a principios del siglo pasado en el diario Crítica, pasando por el montaje y los usos narrativos del cronista Rodolfo Walsh, hasta llegar a los reportajes y perfiles narrativos de jóvenes periodistas como Rodolfo Palacios o Javier Sinay. El análisis de los textos de ambos periodistas permitirá establecer los procedimientos a seguir en la investigación y narración del delito, para realizar una cobertura periodística responsable, efectiva y atractiva para el lector de estos asuntos sociales.

Palabras clave: crónica negra, crónica policial, periodismo narrativo, periodismo de investigación, Argentina, Rodolfo Palacios, Javier Sinay.

\section{Researching and narrating crime in Argentina. Narrative journalism and crime reportage by Javier Sinay and Rodolfo Palacios}

\footnotetext{
Abstract

Crime and felony are ever-present in the media discourse. However, journalism dealing with these issues does not enjoy the same prestige accorded to other genres. Police journalism often
} 
faces a conundrum, as questions of ethics, respect for the victims, and deontological standards come into conflict with morbid fascination, sensationalism, and yellow journalism.

This paper traces the evolution of certain Argentine approaches to police journalism, from the styles introduced at the beginning of the 20th century by the newspaper Critica to the use of montage and narrative by Rodolfo Walsh and, finally, the interviews and profiles written by young journalists like Rodolfo Palacios or Javier Sinay. By analyzing the work of these last two authors, we establish proper procedures for investigating and narrating crime in a responsible, effective, and attractive manner.

Keywords: crime report, narrative journalism, investigative journalism, Argentina, Rodolfo Palacios, Javier Sinay.

\section{Investigar e narrar o crime em Argentina. 0 jornalismo narrativo e a crônica policial de Javier Sinay e Rodolfo Palacios}

\section{Resumo}

O crime e o delito estão presentes de maneira quotidiana no discurso da mídia. Contudo, o jornalismo que abrange estes temas não conta com o prestígio que outros gêneros têm. $O$ jornalismo policial decorre, muito frequentemente, numa encruzilhada pela própria temática. $\mathrm{O}$ respeito às vítimas, a ética ou as regras deontológicas enfrentam-se, na cobertura mediática dos fatos lutuosos, à apelação ao sensacionalismo e ao espetáculo.

O presente trabalho retrata a evolução de algumas abordagens do jornalismo policial argentino que percebemos como relevantes. Desde os novos modos apresentados ao início do século passado no jornal Crítica, passando pela montagem e as práticas narrativas do cronista Rodolfo Walsh, até alcançar as reportagens e perfis narrativos de jovens jornalistas como Rodolfo Palacios e Javier Sinay. A análise dos textos de Palacios e Sinay permitirá estabelecer os procedimentos a seguir na investigação e narração do crime, para realizar uma cobertura jornalística responsável, eficaz e atraente para o leitor desses assuntos sociais.

Palavras chave: crônica policial, jornalismo narrativo, jornalismo de investigação, Argentina, Rodolfo Palacios, Javier Sinay.

\section{Introducción}

En 2015, el periodista argentino Javier Sinay ganó el Premio Gabriel García Márquez de Periodismo en la categoría de Mejor texto por el reportaje "Rápido, furioso, muerto", que había publicado en la revista Rolling Stone. Era la tercera vez que un periodista argentino conseguía este premio, el más importante del periodismo en lengua española. Anteriormente lo habían logrado Josefina Licitra, en 2004 con "Pollita en fuga", y Leila Guerriero, con el texto "El rastro en los huesos", en 2010. Los tres textos galardonados tenían en común el tema del que partían: el delito.

El crimen y el delito están presentes cotidianamente en los medios de comunicación. Pero el periodismo que trata estos temas no suele gozar del prestigio que tienen otros contenidos. La información de hechos luctuosos queda señalada por su propensión al amarillismo, la espectacularización y el sensacionalismo. Sin embargo, el periodismo policial o de sucesos es "inseparable de la actividad periodística" porque en contraposición al tópico 
de que "las buenas noticias no son noticias" las malas noticias siempre lo son. Rodríguez Cárcela (2011) defiende un "tratamiento serio y profesional, alejado de exageraciones y descripciones macabras" (pp. 310-319). Solo el rigor en el abordaje de estos hechos favorecerá un periodismo que puede ser, incluso, de utilidad en la prevención del delito y en los avances en ciencias sociales como la sociología o la criminología.

El asesinato es un buen motor de arranque, tanto para la ficción como para el periodismo literario. El drama, como género clave de la no ficción (Rodríguez Rodríguez, 2012). La violencia, empleada para comprender la condición humana; para dar cuenta de su complejidad. El individuo acorralado, el que busca venganza, el que sufre, el que hace algo brutal por amor... Las herramientas de la crónica permiten profundizar en estos hechos y contar los asuntos importantes que subyacen, aunque pueda tomarse lo atractivo o lo morboso para captar la atención y dar forma a las historias criminales.

Javier Sinay tiene publicado un libro de crónicas breves (fieles al género negro) que puede leerse como una historia criminal argentina. Se titula 100 crímenes resonantes que conmovieron a la sociedad argentina (2010) y recoge asesinatos que van desde 1811 hasta 2009, incluyendo al primero de los “desaparecidos" y el caso concreto de Rodolfo Walsh (Angulo Egea, 2013).

El reconocimiento de la Fundación Gabriel García Márquez (FNPI) a los textos de Sinay, Guerriero y Licitra vendría a confirmar la existencia de otra forma más adecuada de tratar estos temas. Un modo de hacer periodismo que parte del delito para explicar otras realidades y que privilegia el cuidado de las formas en una apuesta por lo narrativo.

En la actualidad, este periodismo narrativo se publica sobre todo fuera de las páginas de los diarios. Si nos adscribimos al territorio argentino, en reportajes que aparecen en revistas como Rolling Stone o Brando y en sitios web como Anfibia o Cosecha Roja. Y también encuentra su espacio en los libros, en colecciones como Mirada Crónica de Tusquets, que edita Leila Guerriero, o Ficciones reales de Editorial Marea, entre otras. Son investigaciones extensas que, siguiendo la estela del periodismo de Rodolfo Walsh, investigan y denuncian la violencia, la corrupción, los crímenes comunes, la delincuencia asociada a la pobreza de las villas miseria u otras tipologías del delito como los feminicidios o las desapariciones.

El presente trabajo traza una evolución en ciertas formas de abordar el periodismo policial argentino, desde los nuevos modos que se plantearon a principios del siglo pasado en el diario Crítica, pasando por la consolidación del género en los escritos del cronista Rodolfo Walsh, hasta llegar a los reportajes y perfiles narrativos de jóvenes periodistas como Rodolfo Palacios y Javier Sinay. Existe, desde luego, una diferencia crucial en el tema de fondo que narran los textos de Walsh, el crimen y la violencia ejercida directamente por el Estado, con el de sus predecesores. Sin embargo, su modo de investigar y construir el relato 
es una influencia decisiva en ellos. El cuidado narrativo y los modos de la literatura policial aplicados a los textos de no ficción sigue presente en el periodismo de Sinay y Palacios.

A través del análisis de los textos de Palacios y Sinay tratamos de establecer los procedimientos a seguir en la investigación y narración del delito, para realizar una cobertura periodística responsable, efectiva, veraz y atractiva para el lector de estos asuntos sociales.

\section{Materiales y metodología}

En primera instancia hemos localizado el período en el que se da cabida a un periodismo que informa del delito y que encuentra en los medios un lugar para desarrollarse. $Y$ hemos profundizado en el contexto periodístico argentino de ayer y de hoy, para extraer el modo como esta práctica se inscribe y se consolida y cuáles son las particularidades del proceso de investigación y narrativas que adquiere y desarrolla. Para ello nuestro análisis se detiene primeramente en el diario Crítica (1913-1962), un vespertino popular y masivo, que sirve de espacio de experimentación para algunas características de este tipo de periodismo que llegan hasta nuestros días, un desarrollo que sin duda hereda elementos de la crónica modernista (Rotker, 2005). La labor periodística de Rodolfo Walsh y un conocimiento claro de su modus operandi es el siguiente escalón. Se hacía imprescindible, para indagar en los procesos de investigación, narración y denuncia de la crónica policial argentina, conocer a fondo su manera de practicar el oficio. Operación Masacre, icono del periodismo narrativo y policial, marca un punto de ruptura en la historia del periodismo argentino y determina, como veremos, sus características posteriores (Adoue, 2011; Ferro, 2010a y 2010b; López Gijsberts y Malharro, 1999, y Amar Sánchez, 1992).

Para reconstruir y profundizar en este amplio marco de análisis fueron clave dos estancias de investigación en la Argentina. Una realizada durante el año 2011 y la segunda en el año 2014. La primera llevada a cabo en la Universidad Nacional de La Plata y la segunda en la Universidad Nacional de Córdoba. Estas estancias aportaron un conocimiento sobre el terreno; nos facilitaron la realización de entrevistas en profundidad y encuentros con los periodistas que son objeto de estudio de caso; así como nos aproximaron a documentación y estudios fundamentales para esta investigación, como Brunetti (2008), Abós (2013), Rivera (1980), Saítta (2013), Schnirmajer (2010), Lanza (2010), Ornelas (2002) y Bencomo (2007), entre otros.

$\mathrm{El}$ análisis de caso que abordamos se ha realizado mediante un modelo híbrido descriptivo-analítico. Se analizan los libros, El Ángel negro (2010) y Conchita. Ricardo Barreda, el hombre que no amaba a las mujeres (2012), del periodista Rodolfo Palacios, y Sangre joven. Matar y morir antes de la adultez (2009), del periodista Javier Sinay, volumen de reportajes por el que recibió el Premio Rodolfo Walsh en la XXIII Semana 
Negra de Gijón, España, en 2010; y trabajamos también otra recopilación suya de reportajes, Las ratas invaden la escena del cuádruple crimen (y otras crónicas) (2016). Este análisis busca desentrañar el modo como estos autores investigan y narran el delito: su faceta narrativa e investigadora. Tratamos de escudriñar qué recogen del pasado y qué presentan como novedoso o desarrollan de manera particular. Recurrimos por tanto a investigaciones del ámbito del periodismo de investigación, Rodríguez (1994), Caminos Marcet (1997), como del periodismo narrativo, Hoyos (2003), Casals Carro (2001), Chiappe (2010) Herrscher (2012) y Angulo Egea (2012, 2013, 2014, 2016, 2017).

\section{La prensa popular argentina: Crítica y el periodista en el lugar de los hechos}

El periodismo que informa sobre el delito fue crucial en el surgimiento del periodismo moderno. En la transición de un periodismo de opinión y partido a otro comercial y de información, el delito se convirtió en un ingrediente clave para su popularización y posterior imposición como canon. A finales del siglo XIX, entre los años 1860 y 1914, se van sentando las bases de un periodismo definido como "periodismo de información" o prensa "popular", "comercial" o "amarilla". El modelo francés, que había sido hegemónico en la prensa mundial, es desplazado desde EEUU por un periodismo que convierte la información en mercancía y al diario en empresa mercantil. Se inicia así la etapa de la industria cultural y la prensa de masas (Brunetti, 2008).

Las características de este "nuevo periodismo de la información", impulsado por Pulitzer desde The World en 1886 y Hearst con The San Francisco Examiner en 1887 son: su bajo precio, el uso del sensacionalismo, el "interés humano" como base de la noticia, la autopromoción, la simplificación de la línea editorial, su vinculación con los intereses de los lectores y unos principios éticos mínimos basados en la búsqueda de la veracidad (Brunetti, 2008; Fernández, 1999).

En la Argentina el diario Crítica es fundamental para entender los cambios en la prensa a inicios del siglo XX y algunas de las características de su "periodismo del delito" que llegan hasta nuestros días. Se trató de un diario vespertino concebido para satisfacer los anhelos informativos de una capa social amplia; nació con vocación mayoritaria y alcanzó los 300.000 ejemplares diarios. Para ello introdujo una serie de renovaciones estéticas, estilísticas y de contenidos que entrañaron una ruptura con la prensa anterior y condicionaron la labor del resto de competidores. "Renovación periodística y chantaje, revolución de formatos periodísticos y demagogia populista son los rasgos que han consolidado la imagen de Crítica" (Saítta, 2013, p. 15).

A la hora de formar un equipo de periodistas, Natalio Botana, antiguo periodista de Última Hora y fundador de Crítica, buscó la calidad narrativa, reclutando a poetas y escritores. En Crítica trabajaron, entre otros, Roberto Arlt, Raúl González Tuñón y Jorge Luis Borges. Surgió un nuevo tipo de periodismo, en el que se apostaba por 
"formas amenas, atrevidas y libres de comunicación (...) es una publicación de sabor indudablemente rioplatense (...) tributaria de los modelos técnicos de la Yellow press norteamericana de Pulitzer y Hearst (...) La fórmula para este equipo era "máxima libertad" y preocupación por los “intereses populares" (Rivera, 1980, p. 368).

Las informaciones sobre el crimen y el delito convertidas en la época en "un ingrediente de seducción para atraer a los lectores a los diarios" (Brunetti, 2008, p. 189), serían el campo de experimentación de la cobertura periodística. En Crítica se potenciarían y se consolidarían algunas de las características fundacionales de estos textos, pero en sus páginas, fundamentalmente, surgiría "un nuevo contrato de comunicación entre el diario y sus lectores, respaldado en una nueva identidad profesional: el periodista en el lugar de los hechos" (Brunetti, 2008, p. 28).

El periodista abandona la redacción para perderse en las calles en busca del "hecho", en este caso el delito: un suceso que acontece inesperadamente dentro de una sociedad y que ha de ser contado inmediatamente. De este se nutrirá la noticia que, además de por la fidelidad de los hechos, se distingue "de otras informaciones y de otros discursos en un doble sentido: la primicia, o la obsesión del presente, y lo inmediato como correlativo de lo reciente" (Brunetti, 2008, p. 75). Pero la labor del reportero, más allá de la búsqueda y narración del suceso, cumpliría otra función importante: su presencia como testigo directo lo dotará de verosimilitud y legitimidad. Se consolidó así una práctica novedosa en la prensa:

el foco del interés se desplazaba del criminal o la víctima, al investigador, que se erigía en dramatis personae. Mediante este recurso, el diario proponía un nuevo código de lectura. El lector pasaba de tener una postura pasiva a intervenir activamente en la investigación, identificándose con el cronista (Abós, 2013, p. 23).

El periodista se convierte en un personaje más dentro de la historia, que incluye atmósferas, detalles, voces o descripciones y exhibe las formas y modos de la labor periodística. Se consolida así la figura del reportero en el lugar de los hechos, una nueva identidad profesional que llega hasta nuestros días y persigue legitimar la veracidad del relato, generalizando una serie de saberes y convenciones sobre su propia práctica. Se crea de este modo una nueva instancia de recepción y una nueva instancia de enunciación que dotará de credibilidad a lo narrado. Una puesta en escena de una nueva situación de comunicación que será exhibida en cada narración del crimen en un nivel extradiegético. Durante el relato del hecho criminal (la diégesis) serán explicitadas la presencia y la descripción de la labor del reportero (Brunetti, 2008).

En estos textos, el periodista se convierte en una suerte de narrador-personaje, alguien que busca y suministra hechos allí donde ocurren, movido por su curiosidad y el deseo de descubrir lo sucedido que guía en sus peripecias al lector. Para la incor- 
poración de este nuevo narrador, los reporteros utilizaron convenciones narrativas de géneros populares y extendidos como el policial o el folletín. De este modo lograron, además de la aceptación y comprensión de los receptores, un modo de narrar. En palabras de Saítta (2013):

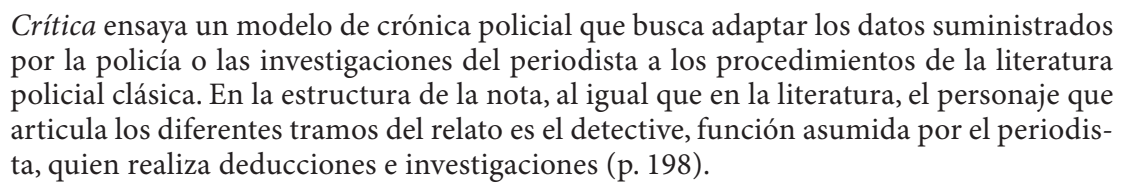

Los préstamos de estos géneros populares no solo transformaron la figura del narrador; en su búsqueda de un nuevo modo de narrar el delito, los reporteros de Crítica adoptaron otras estrategias literarias:

a) Del folletín incorporaron su carácter episódico: explotaron la interrupción para crear suspense e hicieron de la cobertura del caso una especie de novela por entregas.

b) En la literatura policial hallaron un modo de organización interna del relato. Asumieron sus convenciones, una forma de construir los personajes y el "recurso de la hipótesis".

En busca de la resolución del caso, el reportero plantea una hipótesis de partida sirviéndose de lo contado por otros diarios, la versión de policías, víctimas y testigos. Para la construcción de personajes hicieron uso de la descripción y transcripción de los diálogos y explotaron el uso de las "historias de vida" (Saítta, 2013): los protagonistas serían personajes con una psicología y una biografía que se reconstruiría mediante las entrevistas y los diálogos. Fue este un modo de humanizar a la víctima pero también al victimario; en Crítica fueron habituales las entrevistas a criminales y el seguimiento de su vida en prisión (Saítta, 2013; Abós, 2013).

\section{El nacimiento del periodismo policial moderno: Operación Masacre}

El periodismo de Rodolfo Walsh fue innovador por varios motivos. Sus trabajos se consideran el inicio del periodismo de investigación argentino: "Walsh se encargará de buscar datos, los chequeará, confrontará con la versión oficial, detectará contradicciones y finalmente hallará la verdad de lo sucedido. Reconstruirá una verdad que pretendió ser ocultada o tergiversada por los poderes establecidos. Esa 
tarea de reconstrucción (...) define al periodismo de investigación" (López Gijsberts \& Malharro, 1999, p. 22)1.

Operación Masacre anticipaba las características y postulados del New Journalism Por su respeto hacia los materiales documentales (testimonios, grabaciones o documentos), que han de ser comprobables, y la transformación del modo como se presentan. "Los textos ponen en escena una versión con su lógica interna, no son una "repetición" de lo real sino que constituyen otra realidad regida por leyes propias con la que cuestionan la credibilidad de otras versiones" (Amar Sánchez, 1992, p. 14). Se produce en ellos una hibridación entre los procedimientos literarios y los hechos reales, en la que veracidad y riqueza narrativa comparten importancia.

Primaron el mostrar sobre el contar, la sucesión de imágenes y escenas casi cinematográficas (Angulo Egea, 2013) contadas mediante el tiempo verbal del presente histórico y sirviéndose de la técnica del interés sostenido (Casals Carro, 2001). Fueron estas una serie de estrategias narrativas encaminadas a hacer visible la historia para que los hechos hablaran. En el proceso de montaje, posterior a la documentación e investigación, el reportero se servía de los recursos retóricos que pidiera la historia para, como señala David Lodge (1999), "crear la ilusión de que estamos presenciando, o espiando por el ojo de la cerradura, acontecimientos históricos" (citado por Casals Carro, 2001, p. 203).

En este tipo de textos la figura del narrador, el periodista, se transforma: alejado y en oposición a las leyes de neutralidad, objetividad y distancia respecto del hecho narrado, se privilegian la subjetividad y el valor de su punto de vista. La realidad se entiende como una construcción. La verdad, es pues, la verdad de los sujetos que muestran una versión, por tanto, un relato (Amar Sánchez, 1992).

Este "verosímil interno" de la prensa se cuestiona al explicitar su modo de construirse: "La verdad es la que surge de esos testimonios, de su montaje, y no está en una realidad de la que se puede dar cuenta fielmente, sino que es el resultado de la construcción" (Amar Sánchez, 1992, p. 34). A su vez, estos textos suelen surgir de las propias noticias de la prensa, enfrentándolas, al poner rostro y dar voz a sus protagonistas (Amar Sánchez, 1992). Sin embargo, Adoue (2010) señala, en línea con lo expuesto por Romina García en Novela de no-ficción o testimonio, que el punto de desconexión de Walsh con sus pares estadounidenses se debe a la intencionalidad de su obra perio-

\footnotetext{
La intención de Walsh era publicar sus reportajes en la prensa masiva; sin embargo, esta intentó desmentir y boicotear su investigación. La campaña periodística vio la luz en Propósitos y Revolución Nacional, dos publicaciones menores ligadas a la derecha nacionalista (Ferro, 2010a). Tras la campaña, los artículos fueron reagrupados y reescritos con la intención de editarse como libro. Pero ninguna editorial se atrevió con el proyecto y fue otra revista minoritaria, Mayoría, la que publicó Operación Masacre en una serie de nueve reportajes, entre el 27 de mayo y el 29 de julio de 1957. Posteriormente, Walsh retomó Operación Masacre en 1964, 1969 y 1972. En estas reediciones, marcado por el contexto sociopolítico y sus propios cambios ideológicos, cambió, suprimió y añadió partes al texto (Ferro, 2010b; López Gijsberts \& Malharro, 1999). "Se puede afirmar que en Walsh tanto la investigación como su posterior escritura parten de un concepto moral: la verdad debe ser expuesta" (López Gijsberts \& Malharro, 1999, p. 162). Veáse al respecto el trabajo ingente de reconstrucción realizado en el llamado "Proyecto Walsh" http://proyectowalsh.com.ar/.
} 
dística. Mientras el New journalism se centra en la forma, explota lo sensacionalista y demagógico y la noticia en sí separada de la causa, Walsh pone el foco en la denuncia y la búsqueda de las causas, por lo que sitúa su obra dentro de la narrativa testimonial latinoamericana y evidencia sus "propósitos claramente militantes" (pp. 51-52). Este acento puesto en la investigación y denuncia, si bien separa a Walsh en parte del New Journalism de los años sesenta, le acerca en cambio a las prácticas y relatos periodísticos llevados a cabo a principios de siglo XX por los denominados despectivamente como muckrakers, rastreadores de cieno, y le sitúa dentro del periodismo de investigación (Angulo Egea, 2017)2.

Para el relato de Operación Masacre, Walsh recurre a las convenciones narrativas de la literatura policial clásica, pero, al dar cuenta de un crimen de Estado, en el que el culpable es quien representa la ley, se produce el cruce con la novela negra y la inevitable politización de un texto que refleja un conflicto social. El propio título tiene una evidente carga política de denuncia, destaca Ferro (2010b):

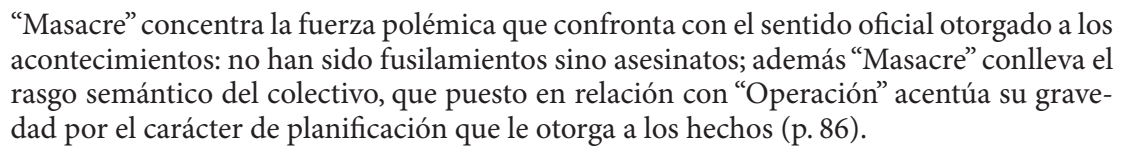

"Un relato es policial cuando en él ocurre un crimen y en torno a este delito se plantea un misterio, un detective lleva adelante la investigación, cuyo desarrollo implica siempre algún tipo de suspenso" (Amar Sánchez, 1992, p. 148). En esta afirmación se encuentran las características del género policial, también del periodismo de Walsh. La ruptura básica entre ambos, sin embargo, se sitúa en el carácter del misterio: mientras el policial oculta la identidad del culpable y el modo como se produjo el crimen, en los hechos que investiga Walsh el lector ya los conoce, por ello el enigma es otro. En Operación Masacre, por ejemplo, consiste en descubrir si se trató de un fusilamiento legal o ilegal. La prueba que determina la ilegalidad del acto se encuentra en el Libro de Locutores de Radio del Estado. Ese elemento, la radio, se utiliza de hilo narrativo en "Las personas", primera parte de Operación Masacre; gracias a ella, el relato se ubica temporalmente y se producen los cambios de espacio. El suspense, que en la investigación de los hechos viene dado por su propio avance, en la narración se logra gracias

\footnotetext{
2 Se trata de un espíritu de denuncia que partía de la labor realizada por periodistas como Nellie Bly a finales del XIX desde The World de Pulitzer. Espíritu que fue recogido por otros periodistas norteamericanos de la época, como Ida M.Tarbell con The History of the Standard Oil Company (1902-1904), o Jack London con The People of the Abyss (1903). Las investigaciones de estos reporteros denominados muckrakers se centraron en la denuncia social de la corrupción de las empresas privadas y de la administración pública. Su trabajo de campo, su labor como reporteros y sus procesos de inmersión, e incluso de infiltración, como sucede con Nellie Bly, señalaron unas formas, unas maneras de acceder a la información. Se comenzaron a poner en práctica ciertos procesos de participación e integración útiles para llevar adelante una investigación periodística compleja. Un tipo de "observación participante" válida para contextos y situaciones en las que es imposible o inviable una observación directa simple (Angulo Egea, 2017).
} 
a dos estrategias: repetición y elusión. Walsh, en la organización del relato, dosifica la información que posee, y el lector conoce, ordenándola según las necesidades narrativas, reforzando así la sensación de intriga y sorpresa; además, gracias a la repetición, de palabras o hechos, introduce variaciones en la sensación que produce su lectura. Esto se refuerza con una economía de lenguaje y unas frases cortas que favorecen el ritmo del relato y que Walsh incorpora también de la literatura policial (Ferro, 2010b; Amar Sánchez, 1992).

Las tres obras periodísticas de Walsh (Operación Masacre (1957), ¿Quién mató a Rosendo? (1969) y Caso Satanowsky (1973) comparten organización interna. Se inician con un apartado en el que, mediante las descripciones espaciales, físicas y psicológicas y el recurso de los diálogos, se presenta a los personajes y el lugar en el que transcurren los hechos, una segunda parte en la que se relata el proceso de investigación y los hechos, y un cierre en el que se explicita la denuncia y se presentan las pruebas y los documentos en que se sustentan. En esta organización, afirma Ferro (2010b):

es posible reconocer un modelo que se corresponde con la oratio judicial, según la codificaba la retórica clásica. Esa articulación progresiva se articula de acuerdo con la dispositio -arreglo de las grandes partes del discurso-, cuya configuración es dicotómica: una primera instancia en la que el enunciador apunta a conmover al tribunal, y que consta de dos partes, el exordio, que abre la exposición, y la peroratio, el epílogo que la cierra; y, una segunda instancia que tiene por función informar y convencer, compuesta de la narratio, el relato de los hechos, y la confirmatio, establecimiento de las pruebas o vías de persuasión (pp. 142-143).

Se trata de una estructura narrativa paradigmática que veremos reproducida en la organización interna de crónicas posteriores. Relatos periodísticos como ¿Quién mató a Mariano Ferreyra? (2014) del periodista Diego Rojas emulan hasta el título y siguen muy de cerca la estructura y el espíritu de denuncia de Walsh.

Las otras partes que configuran estas investigaciones son el prólogo y el epílogo. Los epílogos, en la obra de Walsh, le acercan al periodismo al uso, pues reflejan los hechos desde la narración objetiva e incluyen, sin filtros, el material documental que sustenta la denuncia (Amar Sánchez, 1992; Ferro, 2010). Los prólogos, sin embargo, pueden ser leídos aisladamente como un relato, e inician la narración de la investigación. Explicitan los motivos y el modo en que se desarrolla, y presentan al protagonista: el "narrador-periodista-detective" (Amar Sánchez, 1992). Prólogos y epílogos que veremos transformarse en las manos de los nuevos cronistas argentinos del siglo XXI, que recurren también a estos paratextos (Genette, 2001) para explicitar desde dónde cuentan, quiénes son, qué saben, qué les preocupa y cuál es su bagaje para abordar determinado asunto, así como para incorporar en ocasiones material documental, de carácter legislativo para terminar de construir su relato de los hechos. Un ejemplo paradigmático lo encontramos en la organización, de- 
sarrollo y cierre de la crónica Los Otros. Una historia del conurbano bonaerense (2011), de Josefina Licitra (Angulo Egea, 2013).

Las obras periodísticas de Walsh se construyen desde una primera persona muy marcada, que refleja el testimonio de víctimas y testigos y a su vez relata su propia investigación y escritura. El periodista se convierte, a la manera del detective de la literatura policial, en alguien que busca desvelar una verdad que quiere ocultarse y a su vez persigue la reparación de la justicia. Por ello, a lo largo de la investigación irá aportando datos, conjeturas, indicios o pruebas que forman dos historias, la de la investigación y la del crimen. Reconstruye el asedio que sufren las víctimas y refleja la persecución del reportero a los culpables. La suma de pruebas documentales y testimonios forman y argumentan la denuncia, e interpelan a los lectores y al Estado.

Hay un modo de polemizar y de enfrentarse al discurso oficial muy característico del periodismo de Walsh, afirma Adoue (2010), que destaca también su convicción de que la divulgación de una noticia es "el mejor modo de proteger al denunciante, la tenacidad frente a las barreras que se oponen para impedir la publicación (...) de información que afecte a los mecanismos del poder dominante y (...) la elección del lugar desde donde se investiga y denuncia: el lugar de las víctimas” (pp. 64-65).

\section{El periodismo policial de Javier Sinay y Rodolfo Palacios}

La nómina de grandes periodistas narrativos argentinos es amplia e incluye para la crónica policial nombres de la importancia de Tomás Eloy Martínez u Osvaldo Soriano -ambos se acercaron a la investigación del delito en obras como La pasión según Trelew o El caso de Robledo Puch, respectivamente-, Martín Caparrós, María Moreno o Leila Guerriero. En el policial, además de Arlt y Walsh, los propios cronistas policiales destacan a autores menos conocidos como Juan José de Soiza Reilly, Fray Mocho, Gustavo Germán González, Emilio Petcoff o Ricardo Ragendorfer.

En la actualidad, Rodolfo Palacios y Javier Sinay son dos de los máximos exponentes de la crónica negra o policial argentina. Ambos forman parte de una generación de cronistas que, como Josefina Licitra, Sebastián Hacher o Cristian Alarcón, entre otros, se encargan de narrar los otros fenómenos sociales que se producen en la gran megalópolis porteña, huyendo de los apriorismos y estereotipos del discurso de los grandes medios. Lo hacen desde la inmersión y la especialización, bebiendo de disciplinas como la sociología o la etnografía en su labor de investigación y reporterismo, y de las herramientas de la literatura en su escritura. Su periodismo parte de una defensa de la mirada propia, de la subjetividad, apoyada en un prolongado trabajo de campo y documentación y de la sinceridad de una voz que no oculta sus contradicciones, dudas o diferencia de clase social. Estos cronistas se acercan a realidades sociales que les son ajenas para, desde la honestidad y el espíritu humanista, dar voz a los que no la tienen y 
denunciar situaciones silenciadas o desconocidas (Angulo Egea, 2013). Recogen, como veremos, la mayoría de las características narrativas y las formas de abordaje detectadas en el diario Crítica y la estructura interna y el espíritu de denuncia de Walsh. Aunque el crimen y el delito no son en la Argentina de hoy parte de una política de Estado, como denunciaba la obra de Walsh, hoy los cronistas siguen develando y denunciando los rincones más oscuros de la sociedad.

Rodolfo Palacios ha trabajado en la sección de "policiales" de varios medios, como La Razón, El Atlántico, Perfil o Crítica de la Argentina y ha colaborado en revistas como Playboy, Orsai o Brando. En la actualidad trabaja como editor y asesor de asuntos policiales para películas y series como El clan (2015) o Historia de un clan (2015). Su periodismo tiene la particularidad de centrarse en la voz de los criminales. Son frecuentes sus perfiles de asesinos o ladrones célebres, como los aparecidos en Adorables criaturas (2012), Sin armas ni rencores (2014) o El clan Puccio (2015). En este estudio nos ocupamos de dos títulos en los que explota su faceta de perfilador, especialidad que ha provocado que se le apode como el escriba del hampa o el biógrafo de los criminales: El Ángel negro (2010), que cuenta la historia de Carlos Robledo Puch, el asesino en serie más célebre del país, y Conchita (2012), un libro en el que reconstruye el crimen del odontólogo Ricardo Barreda, que asesinó a su familia en 1992, y relata su nueva vida en pareja una vez recuperada la libertad. La biografía criminal y la vida dentro y fuera de la cárcel es el tema principal de ambos libros, pero, en su narración, Palacios reflexiona sobre el crimen y los fenómenos asociados a este, como la vida carcelaria, la repercusión cultural y popular de los crímenes y criminales famosos; incluso aborda patologías como la enclitofilia: la atracción que sienten algunas mujeres, como Berta, la novia de Barreda, por los criminales.

Javier Sinay ha trabajado en las redacciones del Suplemento Sí y Rolling Stone y en la actualidad es enviado especial del diario mexicano El Universal. Ha publicado reportajes sobre el delito en numerosos medios, como Brando, Gatopardo, Anfibia u Orsai, y los libros 100 crímenes resonantes que conmovieron a la sociedad argentina (2010), Los crímenes de Moisés Ville (2013), y Sangre joven (2009), que analizamos en este estudio junto a tres reportajes fundamentales incluidos en el recopilatorio Las ratas invaden la escena del cuádruple crimen (y otras crónicas) (2016): "Sangre de amor correspondido", publicado por Rolling Stone en 2011, "Cuatro mujeres muertas", publicado primeramente en la desparecida revista Orsai en 2013, y "Rápido, furioso, muerto", aparecido en 2014 también en Rolling Stone, investigación por la que recibió el premio Gabriel García Márquez de Periodismo en 2015.

Sinay practica un tipo de periodismo que, desde la investigación concreta de un crimen, busca dar respuesta a fenómenos sociales más amplios. Se sumerge en hechos violentos para comprender la condición humana y dar cuenta de su compleji- 
dad. En Sangre joven, el relato de seis crímenes le permite hablar de la violencia entre jóvenes, las diferencias existentes entre habitantes del norte o el centro argentino y denuncia la realidad de la vida en las villas miseria, entre otros temas. Este cronista encuentra en el género policial su manera de contar historias, de describir la criminalidad y adentrarse en las contradicciones de la condición humana. Su abordaje del tema policial tiene ese lado intrínsecamente humanista. Parte de la nota roja o el suceso pero sin dejarse llevar por el morbo y el sensacionalismo. Consciente de la delgada línea que los separa, no puede negar la fuerza con que estos actos violentos le impactan y disparan su interés por la comprensión del individuo puesto al límite (Angulo Egea, 2013).

Nos centramos en el modus operandi de Javier Sinay y Rodolfo Palacios; en desentrañar qué heredan de las características del género caracterizado hasta este momento. Nos detenemos tanto en el estudio del trabajo de campo y de documentación que requieren sus investigaciones, como en las técnicas y estrategias discursivas de su proceso narrativo. Algunos aspectos clave, como veremos, son la libertad formal con la que trabajan, la búsqueda de la amenidad que pretenden, el impacto que genera el reportero en el lugar de los hechos, el uso de recursos propios de la retórica y de la poética y el desarrollo de la subjetividad. En cuanto al uso de elementos narrativos típicos de la literatura policial, destaca el empleo del narrador-periodista-detective y la necesidad de denuncia social de los textos de Walsh.

\section{La investigación periodística y el trabajo de campo}

Una de las características básicas del periodismo del delito en el que se inscriben las obras de Rodolfo Palacios y Javier Sinay es la distancia temporal con el hecho narrado. Criterios periodísticos como la cercanía temporal o la proximidad ceden en sus trabajos ante factores como el simbolismo, la necesidad de denuncia o la universalidad de los hechos investigados (Hoyos, 2003). El tema que tratan ya es conocido y los medios masivos se encargaron de cubrirlo. El detonante es la curiosidad del periodista, el deseo de profundizar en las causas y el contexto de un hecho delictivo cuya cobertura mediática cesó. En el prólogo de Sangre Joven, Sinay (2009) explicita esta relación:

Con la aridez de una noticia sombría, o alguna vez también con la urgencia de un título catástrofe, los crímenes que surgen a continuación han aparecido en los medios y conmovido a la sociedad, en mayor o menor medida (...) Los acontecimientos fueron publicados en la sección de policiales, donde muchas veces pasaron a ser una noticia más (...) Pero para mí no lo fueron: durante un año investigué seis historias en las que el homicidio fue un caso extremo (p. 15). 
En las líneas anteriores ya se advierten algunos elementos propios del género, como la apuesta por la primera persona y la exposición clara de los motivos subjetivos que desencadenan la investigación. "Lo que perseguí, en cambio, fueron las claves para retratar ese universo juvenil y a sus personajes, dejando de lado los estereotipos" (Sinay, 2009, p. 16). Los prólogos, como ya se vio en el caso de Walsh, son cruciales en este tipo de obras; para Amar Sánchez (1992) se trata de:

Un relato de cómo se gesta y se desarrolla la investigación; posterior a los hechos, los precede en el texto y se constituye ella misma en acontecimiento. Allí también se van conformando los sujetos protagonistas, y en especial una figura clave que adquiere absoluta primacía: el narrador-periodista-detective. Él condensa múltiples funciones: narra, construye, investiga (...) y sostiene, como un hilo conductor, la narración, la búsqueda "de una verdad oculta" (p. 94).

Sobre el pacto de lectura establecido en estos textos introductorios lo interesante consiste en ver cómo estos textos preliminares son la marca evidente de que el relato no es una ficción, porque su autor, el periodista, nos acaba de decir en primera persona que lo que el lector va a comenzar a leer es real y que da fe de ello (Angulo Egea, 2012).

La fuente primera de la cual beben estas historias es, entonces, la propia noticia periodística. En el primer acercamiento a los hechos el periodista repasa las hemerotecas en busca de los detalles del caso. El texto siempre refleja esta influencia, en ocasiones mediante una visión crítica o irónica de la profesión. Rodolfo Palacios (2012) recuerda de este modo la cobertura mediática que sucedió al caso de Barreda:

\footnotetext{
Durante los primeros días de su detención, los diarios contaron que Barreda estaba muy mal y que le había dicho a su abogado: "No aguanto más, vivir con esas mujeres era un infierno, me quiero morir". También informaron que llegó a tener diez amantes en dos años (...). Los periodistas que cubrieron el caso contaron que cuando él se subía a la escalera para podar el árbol, su esposa le decía: "Ojalá te caigas y te mates". (...) Los medios publicaron que matar lo había excitado: por eso tuvo sexo con su amante (p.45).
}

Habitualmente se asocia el periodismo de investigación con los grandes escándalos y las tramas de corrupción, fundamentalmente políticas, desveladas por los medios. También suele afirmarse que todo buen periodismo es inevitablemente de investigación. Pero el periodismo de investigación tiene sus propias características: requiere de una amplia labor de investigación y de reporterismo en la que el periodista evita las fuentes oficiales y se centra en aquellas que están ocultas o son ignoradas y trabaja con unos plazos temporales ajenos a la rutina informativa. Su objetivo final es poner en la esfera pública hechos que acontecen en la sociedad y que los grandes medios y el poder ignoran o silencian. Para ello se sirve de distintas técnicas y herramientas, se autoexige precisión y busca respuestas más allá de lo visible a simple vista (Caminos 
Marcet, 1997). El objetivo final, por tanto, es denunciar hechos que la opinión pública desconoce y generar debates en torno a determinados asuntos. Con su investigación del asesinato de Axel Lucero, en "Rápido, furioso, muerto", Javier Sinay, por ejemplo, logró llevar a la agenda pública y política el asunto del uso de armas reglamentarias por policías fuera de servicio.

Rodríguez (1994) define fuente como "toda persona que de un modo voluntario y activo facilite algún tipo de información a un periodista [y] todo depósito de información de cualquier tipo que sea accesible y consultable por el periodista (prensa, libros, archivos diversos, etc.)" (p. 67). Establece una clasificación de las fuentes según distintos criterios: fuentes documentales (aquellos documentos o archivos a los que el periodista tiene acceso), y fuentes personales (dentro de las que distingue entre fuentes asiduas y ocasionales, según el grado de utilización y relación con ellas); fuentes puntuales y generales (es decir, de interés en un momento concreto o consultadas en múltiples ocasiones); fuentes confidenciales, que exigen su anonimato, y fuentes privadas y públicas (según su acceso sea restringido al periodista o accesible a todos). Suma las fuentes implicadas, cuando han vivido en primera persona los hechos, o ajenas, si, pese a no vivir el hecho, pueden hablar de él. En este último grupo están las fuentes técnicas, que aportan la voz del conocimiento o la experiencia en una determinada materia (Rodríguez, 1994).

Con respecto a las fuentes y su clasificación, seguimos a Rodríguez. En cuanto a fuentes documentales para las investigaciones periodísticas que abordamos, lo primero, como se ha visto, es recurrir a las noticias publicadas, que suelen ser la primera fuente consultada por el periodista. Dado el tipo de hecho noticioso que tratan los reportajes que analizamos, sucesos que implican procedimientos judiciales o policiales, informes físicos o psicológicos, etc., el uso de "fuentes documentales" es básico y constante en estos libros. El modo de presentarla, sin embargo, varía. A veces aparecen de manera textual, como las cartas que Marcelo Bernasconi, encarcelado tras asesinar a su madre y hermano, que le hacían imposible la existencia debido a su homosexualidad, envía a su amiga Irma. Esas confesiones de Marcelo sirven para abrir y cerrar la crónica de Javier Sinay (2016) “Sangre de amor correspondido" recogida en Las ratas invaden la escena del cuádruple crimen: "Después del hecho sentí mucha paz. Ya nunca más tuve esas vocecitas atrás que me recriminaban todo. Sé que voy a perder mi juventud acá dentro. Y lo primero que haga cuando salga va a ser ir al cementerio para comprobar con mis ojos que los maté" (p. 151). En otras ocasiones se convierten en relato. Sinay (2009), en "Querido diario. Nueve puñaladas en la bailanta S'Combro", transforma así la labor del perito reflejada en el acta judicial: "El perito busca más sangre, o alguna navaja. No encuentra nada. Al final, llegan al fondo y abren la puerta de emergencia. La luz los sacude y los devuelve al día" (p.77). Estos documentos oficiales también pueden 
aparecer de forma dialogada. Palacios (2012) transforma de este modo la confesión de Barreda al subcomisario Ángel Petti, incluida en el acta policial:

- Dígame quién se lo dijo.

- Se lo digo con una condición.

- ¿Cuál?

- Que usted me diga dónde está la escopeta con la que mató a su familia.

- La tiré en Punta Lara (p. 30).

Es común en las obras de Palacios y Sinay la inserción de elementos que parecen externos al relato de los hechos a primera vista, pero que, por el contrario, plasman elementos significativos. Es habitual en las investigaciones de Rodolfo Palacios que incorpore elementos de cultura popular, como canciones, películas o libros. Por ejemplo, en Conchita reproduce la letra del tango "Desencuentro" que, Barreda, en conversación, destaca como su preferido. La letra, dice: "Quisiste con ternura y el amor/te devoró de atrás hasta el riñón./ Se rieron de tu abrazo y ahí nomás/te hundieron con rencor todo el arpón./Amargo desencuentro, porque ves que es al revés..." (Palacios, 2012, p. 130). A simple vista podría definir a un hombre sentimental, romántico, pero este tango encaja perfectamente con la versión del propio Barreda sobre sus crímenes: la actitud de desprecio y maltrato de su esposa e hijas le enloqueció y causó el crimen, aunque la gente considere que fue un hecho premeditado. En ese capítulo, titulado "Que los cumplas feliz", el periodista recoge la influencia de la "figura del criminal" de Barreda en la cultura popular argentina. Introduce fragmentos de canciones o poemas dedicados a él y nombra los libros u obras de teatro que le rememoran. Por su parte, Sinay, para cumplir el objetivo expresado en el prólogo de reflejar a una generación, la suya, recurre a las letras de las cumbias villeras ${ }^{3}$ o el llamado rock nacional argentino e indaga en la historia de estos géneros musicales en el país. El periodismo narrativo actual se sitúa así entre el melodrama y la música popular, cuyas crónicas son:

las fabulosas historias reales de una América Latina de la subalternidad, que hace propio el sentimiento de latencia e identidad de las nuevas grandes urbes del subcontinente después de dos décadas de neoliberalismo. Un retablo, sin duda, de gran interés humano y más que apasionante, por lo que de captura de la vida de ese universo periférico y marginal nos muestra, para la legión de lectores fieles seguidores de las nuevas letras y formas narrativas de la escritura latinoamericana (Sierra Caballero \& López Hidalgo, 2016, p. 925).

Sin embargo, tal y como vimos en Walsh, el elemento decisorio en este tipo de periodismo son las fuentes personales. Los testimonios, obtenidos mediante entrevista, son el factor clave que permite ampliar y profundizar en la historia, entendida como

\footnotetext{
La cumbia villera es un estilo musical surgido en la Argentina a finales de la década de 1990. Es una variante de la cumbia, con influencias de otras músicas populares latinoamericanas, cuya temática y lenguaje están muy ligadas a la vida en los barrios más humildes de Buenos Aires y otras grandes ciudades.
} 
un relato de acciones humanas que transcurren en un tiempo concreto (Hoyos, 2003). La peculiaridad del periodismo de Rodolfo Palacios son sus contactos con el mundo criminal, lo que le permite disponer de fuentes dentro de las cárceles argentinas. En El Ángel Negro se contacta con algunos presos célebres a los que entrevista para conocer cómo es la estancia de Robledo Puch ${ }^{4}$ en la cárcel. Podemos leer, por ejemplo, a Rubén Alberto de La Torre, integrante de la banda que protagonizó el robo al Banco Río de la localidad bonaerense de San Isidro, afirmar: "Le hicieron la vida imposible. La cana lo quemó con la picana y los presos lo maltrataron. Era de clase alta, rubiecito, había leído mucho. Eso muchos no lo perdonan" (Palacios, 2010, p. 188). Sinay y Palacios consultan habitualmente la voz de otras "fuentes técnicas". En "Cuatro mujeres muertas", recogido en Las ratas invaden la escena del cuádruple crimen (y otras crónicas), Sinay (2016) entrevista al abogado penalista que de facto ejerció de fiscal, Fernando Burlando: "Yo ya tenía un interés por las cuestiones relacionadas con la mujer. Una buena forma de buscar justicia es estando presente en los hechos en los que las víctimas son mujeres y son atacadas indiscriminadamente" (p. 27). A lo largo de los dos relatos, las voces de fiscales, abogados, policías o forenses permiten componer una radiografía de los mecanismos legales que hay después del crimen.

Sin embargo, son las voces de las fuentes implicadas, según la clasificación de Rodríguez (1994), las que dotan de riqueza y profundidad al texto. De nuevo, al igual que en el periodismo de Walsh, la búsqueda de los testigos, familiares o víctimas permite descubrir la verdad y reconstruir el suceso. El reportero para lograr un relato fiel de estos testimonios deberá "sumergirse sin prejuicios en la cultura de los otros con el fin de comprenderla y aprehenderla. Esto significa lograr una empatía, un saber situarse frente a los otros" (Hoyos, 2003, p. 103). Se trata del "poder civilizador" de la empatía en estos procesos de inmersión (Angulo Egea, 2014). En el reportaje "10 B Sociales. Masacre de Carmen de Patagones", de Sangre Joven, Javier Sinay (2009) habla con Claudia, madre de uno de los supervivientes de aquel tiroteo 5 . En el diálogo, la madre rememora lo que sintió aquel día:

Yo no me di cuenta de mucho. El shock fue tan grande que hay muchas cosas de las que no me acuerdo. Sí me acuerdo de una emoción que puedo registrar desde ese momento hasta hoy: el miedo. El miedo (...) de que me digan "Tu hijo se muere", de que cada vez que salía la enfermera me iba a decir "se murió" (p. 66).

\footnotetext{
4 Carlos Eduardo Robledo Puch (Buenos Aires, 19 de enero de 1952) es uno de los mayores criminales de la historia argentina. Entre mayo de 1971 y febrero de 1972 cometió 11 asesinatos, participó en una violación y una violación frustrada y protagonizó diversos atracos y robos. En 1972 fue condenado a reclusión perpetua por tiempo indeterminado. En la actualidad, sigue cumpliendo condena en la Cárcel de Sierra Chica, lo que le convierte en el reo con mayor antigüedad de las cárceles argentinas.

5 El 28 de septiembre de 2004, en la localidad de Carmen de Patagones, en el sudoeste de la provincia de Buenos Aires, Rafael Solich, un estudiante de 15 años, disparó con una pistola perteneciente a su padre a varios compañeros de su instituto, el No 202-Islas Malvinas. Durante el tiroteo murieron tres adolescentes y cinco resultaron heridos.
} 
Y también, expone a Sinay su denuncia: "El chico hizo algo así porque estaba loco, pero la parte más fea de todo esto era que se podía haber prevenido. Porque todos los adultos responsables que estaban ahí adentro sabían que el chico estaba loco" (p. 66).

Es mediante la relación continuada con los entrevistados y la observación de los lugares en los que se desarrollan los hechos como el reportero logra la "inmersión" que le permite obtener todos los ángulos de la historia y sus protagonistas (Hoyos, 2003). Solo con esta estancia prolongada consigue ser testigo de la escena significativa o el dato que persigue: Palacios, tras días de conversación con Ricardo Barreda ${ }^{6}$, logra que él nombre a la familia que asesinó y ahora pretende olvidar. Gracias a la confianza que se establece entre ambos y tras una pregunta anodina, sucede:

- ¿No le gustaría tener un perro?

- Sí. Hace mucho tiempo que tengo ganas. Una vez quise tener un perro, pero ellas me dijeron que no. Me sacaron cagando: iguau guau guau guau guau!

Barreda ladraba como un perro pequeño, "ellas" eran su esposa y dos sus hijas (Palacios, 2012, p. 126).

Por su parte, durante la investigación del asesinato en la "bailanta S'Combro", Sinay (2009) consigue que uno de los testigos, Hernán, le muestre las cicatrices de las puñaladas que recibió esa noche: "Las cicatrices que lleva en su espalda están ahí para que no siga olvidando", escribe (p. 92).

Esta relación con los protagonistas de la historia nos permite fundamentalmente acceder a espacios de la vida privada de los protagonistas que enriquecen la historia, en una faceta espacial y social. Así, por ejemplo, gracias a la entrevista de Sinay a Araceli, la novia de Axel Lucero, víctima en el reportaje "Rápido, furioso, muerto", recogido en Las ratas invaden la escena del cuádruple crimen (y otras crónicas), podemos conocer cómo es el día a día y las biografías de los habitantes de las villas miseria argentinas. Pero también esta relación continuada puede derivar en momentos tensos que ayudan a perfilar al entrevistado: "Entró Robledo. Cerró de un portazo. - ¡Vos sos imbécil! ¿Te falla la cabeza? ¿Por qué mierda no venís cuando decís que vas a venir? ¿Sabés lo que es la espera para alguien que pasó la mayor parte de su vida en la cárcel?" (Palacios, 2010, p. 225).

\section{El relato de los hechos}

Las crónicas de Rodolfo Palacios y Javier Sinay son herederas de un tipo de práctica periodística en la que el periodista ingresa en la diégesis, en el relato, como un personaje más. Este es el factor que pone en común al cronista del Modernismo (Rotker, 2005)

\footnotetext{
El odontólogo Ricardo Alberto Barreda (La Plata, 16 de junio de 1936) asesinó el 15 de noviembre de 1992 a su esposa, Gladys McDonald, sus dos hijas, Cecilia y Adriana Barreda, y su suegra, Elena Arreche. En 1995 fue condenado a prisión perpetua y desde 2011 disfruta del régimen de libertad condicional.
} 
con el "periodista en el lugar de los hechos" (Brunetti, 2008) de la época de Crítica y el "narrador-periodista-personaje" (Amar Sánchez, 1992) que encarnaba Rodolfo Walsh.

Sinay y Palacios utilizan en la actualidad idénticas estrategias a la hora de afrontar el relato y elegir el lugar desde el que será narrado. En sus textos, como en los de sus predecesores, prima, fundamentalmente, el uso de la primera persona y del narrador homodiegético. Este gesto no rompe el pacto con el receptor de sus textos siempre que el periodista le haga partícipe de esta elección. Más allá de la declaración de intenciones expuesta en los prólogos, el cronista muestra su participación en el relato y la elección de su voz, para alejarse de la supuesta neutralidad del periodista clásico, insertándose en la historia y haciéndole partícipe del desarrollo de la investigación. El periodista se presenta, también, como una suerte de mediador, un gestor creativo, que organiza y ordena todo el material que dispone tras la labor de documentación y el trabajo de campo (Angulo Egea, 2016).

De este modo cuenta Palacios (2010) el final de su relación con el Ángel Negro: "En ese momento no lo supe, pero era la última vez que veía a Carlos Robledo Puch. Habían pasado ocho visitas, cuarenta y cinco cartas y diez o quince llamados desde aquel primer encuentro en el que pensó que yo iba a matarlo" (p. 244). Al más puro estilo del policial clásico, Sinay (2009) informa, así, de sus avances en la investigación sobre el violador de La Plata en "El niño que ríe. El caso del Hombre Araña de La Plata": "Tenía solo un dato que había podido rescatar luego de una charla con un policía que tuvo la gentileza de revisar su archivo" (p. 155).

Pero elegir el uso de la primera persona no solo implica explicitar la presencia del narrador en el texto, también les permite expresar sus opiniones, proyectar su mirada sobre los hechos. "El narrador en primera persona, que no necesariamente es el protagonista, tiene licencia para reflejar opiniones, pues, en este caso, son parte de la acción. Su tono no es impersonal. Se implica, toma posición" (Chiappe, 2010, p. 33). "Ningún periodista vino a tocar la puerta luego de la muerte de Brian: nadie quiso sacarle la careta al Hombre Araña. Acaso a la opinión pública le alcanzaba con el tiro en la nuca y el fin de los ataques" (Sinay, 2009, p. 155), reflexiona el periodista sobre la actuación de los medios, antes de llamar a la puerta de la casa del violador de La Plata. Palacios (2012) va más allá y, para intentar entender qué sintió Barreda al disparar, se apunta a clases de tiro, y entra en el espacio del narrador-protagonista: "Me prometo a mí mismo no volver a disparar un arma. No maté a nadie pero me siento vacío. No soy capaz de imaginar cómo se sintió Barreda después de matar a cuatro personas" (p. 39).

Sin embargo, para que este pacto entre cronista y lector funcione, para que este admita la subjetividad de quien escribe y decida creer su relato, además de demostrar la veracidad de las pruebas y los procedimientos es necesaria la "empatía" (Angulo Egea, 2014). Las estrategias para lograr que el lector conecte con el periodista son variadas; 
Rodolfo Palacios, por ejemplo, suele servirse de la autoparodia, riéndose de sus carencias o de las situaciones que se producen en los terrenos del hampa en los que incursiona, convirtiéndose en una suerte de "periodista clown" (Angulo Egea, 2014). Ejemplo de ello es el siguiente monólogo interior: "Mientras el viejo vuelve a alimentar a sus pajaritos, pienso qué ocurriría si le insulto. Me imagino diciéndole: -Dale, Conchita, deja de alimentar a la cotorra. Y él mirándome con odio buscando algo para rompérmelo en la cabeza" (Palacios, 2012, p. 80). O, en una estrategia casi opuesta, se muestra duro y cínico a la manera de los escritores del hard-boiled o policial negro norteamericano: "El domingo en que mató a su familia iba a oler al tuco de los fideos. Pero ese día todo olió a pólvora y al hedor que emanan los cadáveres. Los aromas que ese día cubrieron el hogar donde antes vivía una familia provenían de las armas que se enfriaban como los cuerpos de las mujeres" (Palacios, 2012, p. 70). Javier Sinay (2009), en "Los amantes de Villa Pueyrredón. El crimen de la discoteca El Teatro", dentro de Sangre Joven, se proyecta ante el lector como un hombre apocado ante la inminente aparición de "la Pimpollo", la despampanante chica que desencadenó la tragedia y que parece marcar los tiempos del encuentro: "Desde algún lugar la Pimpollo se rio; y se sorprendió de que yo no fuera rubio, como le habían dicho. En un segundo me sentí dentro de una película, haciendo el papel de un ratón ante un gato. Cazador cazado" (p. 44).

Sin embargo, el periodista en estos textos se transforma en personaje, no en protagonista. Su historia es la de la investigación, la que guía y articula el relato; el protagonismo recae en los otros personajes. Como apunta Herrscher (2012):

Pasar de las fuentes a los personajes y de las declaraciones a las escenas casi teatrales donde la gente se cuenta cosas es entrar en el mundo del periodismo narrativo (...) nos permite (...) entrar en su mundo interior, en su punto de vista, y lograr, tal vez que el lector se identifique con la persona a la que le pasan las cosas que cuenta el periodismo (p. 239).

El periodismo de Sinay y Palacios está cargado de voces, víctimas, testigos, victimarios, autoridades, etc., que construyen una historia coral que va dando forma al relato.

El proceso por el cual estas fuentes se van transformando en personaje se da gracias al uso del diálogo y la descripción. El objetivo del narrador es lograr que el lector sienta con sus propios sentidos lo que está leyendo, conseguir crear una escena tan real como la vida. Una imitación o mímesis. Gracias a un adecuado manejo del diálogo y la descripción, el lector creerá oír la voz de los protagonistas y visualizar el espacio en el que sucede la acción (Hoyos, 2003). Por ello, como un etnólogo, durante sus encuentros con las fuentes el cronista observa los detalles reveladores que le permiten caracterizar del mejor modo posible al personaje analizado. Rodolfo Palacios está especializado en los perfiles periodísticos, su periodismo busca, con los retratos de criminales, entender el crimen y sus fenómenos anexos. Parte de la historia de Conchita se centra en la relación entre Barreda y su novia, Berta. De este modo, describe físicamente a Barreda en plena acción: “Se detuvo y le costó enderezar la columna 
para mirar hacia arriba. Su postura era desarmada, como una marioneta. Quedó como haciendo equilibrio" (Palacios, 2012, p. 93).Y así, con una escena cotidiana del nuevo hogar de Barreda, describe la relación de la pareja:

Es sábado por la mañana y va por su segunda pava de mate. Berta va por el cuarto o quinto sueño, quién sabe cuándo despertará. Eso a Barreda puede llegar a irritarlo, como la puerta que divide la cocina del pasillo que comunica la pieza donde duerme su novia. Esa puerta, que tiene la madera hinchada, se abre cada tanto (Palacios, 2012, p. 63).

La puerta se convierte en una metáfora de la distancia entre Barreda y Berta, y esa distancia se remarca con la descripción psicológica de ambos que incluye la escena.

La otra construcción literaria de estas crónicas del delito son los escenarios, el lugar donde se desarrolla la acción. En ellas, de igual modo que en la construcción de los personajes, no solo se da cuenta de lo aparente, se busca un significado mayor. Javier Sinay (2016) describe de este modo la villa por la que deambulaba la víctima de "Rápido, furioso, muerto":

El corazón del barrio El Carmen es su plaza, cuyo paisaje se asemeja mucho a la luna en un sueño decadente. Está sobre un manto de césped carcomido como el lomo de un perro con sarna; un techo de cielo gris envuelve a los árboles sin hojas y una pasarela de cemento que se enrula como una serpiente" (p. 114).

"La crónica prepondera la historia de un personaje. Le rescata de la multitud y usa su rostro para retratar a ese colectivo" (Chiappe, 2010, p. 12). En su descripción, Sinay se sirve del ambiente en el que vivía su personaje para denunciar la marginalidad y el abandono de las villas miseria.

Con Operación Masacre comentamos que uno de los puntos fuertes del relato periodístico de Walsh era el modo como se construía la historia. La estructura interna de esta obra periodística, tributaria de los modos de hacer de la literatura policial, guiaba al lector hasta la resolución del enigma: ¿fue un crimen legal o ilegal? La estructura del relato, la planificación en su construcción, la tensión, el suspense y el conflicto son elementos decisivos en el periodismo narrativo. "El tiempo real obedece a un orden cronológico, inmutable, que no es posible alterar, abreviar o alargar. El narrativo entremezcla el tiempo psicológico y el real, y se puede combinar, desordenar, acelerar o retrasar, por medio de estrategias temporales" (Chiappe, 2010, p. 126).

El reportaje "La mate porque era mía", de Javier Sinay (2009), es un ejemplo claro de la utilización de algunas de estas estrategias comunes en el género policial. La historia comienza con el reportero viajando en taxi a Altos de San Lorenzo, una villa en la periferia de La Plata; allí aparece una anciana, Francisca. Al finalizar ese párrafo se adelanta: "Ella tiene una historia para contar, muy a su pesar. La contará lentamente, con una cálida tonada santiagueña y una furia suave, acaso disimulada" (p. 114). Después, 
en el tercer párrafo, continúa: "El pasado fue maravilloso, parece pensar Francisca antes de detenerse para iniciar el tramo más penoso de su relato", y concluye el párrafo: "Pero yo pienso que la gente de afuera seguro es más buena que la de adentro: yo todavía no puedo creer lo que me pasó a mí con alguien de mi propia familia" (p. 114). En las siguientes páginas, se va relatando la vida de Francisca y su familia, y aparecen dos personajes que Sinay caracteriza de esta manera: "Era la chica más linda de Altos de San Lorenzo y lo sabía" y "El santiagueño no demostraba sus emociones, ni siquiera cuando la pasaba mal: era silencioso y observador" (p. 118). Son Silvana y su primo Jaime, protagonistas de esta historia, aunque no conoceremos el motivo hasta diecisiete páginas después, cuando aparece el cadáver de ella. Antes, mediante el uso de distintos tropos, como la elipsis o la analepsis o flashback, y cambios en el tiempo narrativo, habíamos conocido la historia secreta de amor de los primos, a nuevos personajes como el nuevo novio de Silvana y su historia paralela de amor, la desaparición de Silvana, el inicio de las pesquisas policiales, etc. Indica Chiappe (2010): "El misterio no funciona cuando se oculta información. El misterio se consigue cuando abunda esa información, cuando existen visiones, conjeturas que intrigan, que incitan a creer que lo normal ha sido trastocado" (p. 148). Sinay (2009) logra esa atmósfera de intriga y suspense aportando datos sueltos que van avanzando un desenlace trágico. Por ejemplo, en un diálogo con Gaspar, el novio de Silvana: "Pero también es verdad que, como ella era más grande que yo, no había garantías de que la relación pudiera durar" (p. 123), y concluye el periodista: "Y así fue: la relación que mantuvieron se prolongó solo por dos semanas" (p. 123). Sinay (2009), en los momentos previos a conocer el desenlace fatal reconstruye en una escena el último encuentro entre los primos:

Jaime le hizo un planteo final a su prima: le dijo que no podía verlo con otro, quería que dejara a Gaspar. Pero ella no quería hablar más del tema y no se guardó nada: ‘Cornudo!”, le gritó, “¡Crédulo!, se burló; y hasta le dijo que todo este tiempo le había estado usando. Jaime se desesperó: implosionó (p. 132).

En otro sentido, Rodolfo Palacios (2012) se sirve del suspense para dilatar la aparición de Berta, la novia de Barreda en escena. A lo largo de los primeros capítulos el periodista la introduce en el relato constantemente, aunque ella nunca aparece. Avanzada la historia, Berta adquiere un carácter protagónico, aunque su primera aparición contribuye a aumentar la intriga de un modo bastante cómico: "De pronto ocurre lo impensado, Berta se despierta, ojerosa, bostezando y desesperezándose, quizá en busca de una medialuna o un bizcochito de grasa. Pero no. Es solo un amague. Saluda con la mano y vuelve a dormir" (pp. 76-77).

El estilo narrativo retoma como estrategia el orden cronológico que el estilo informativo había resumido e invertido. El relato sigue un orden lógico y temporal potenciado por el uso de verbos en tiempo presente en el que, pese a la inserción de 
relatos secundarios y saltos temporales, siempre se regresa al presente. De este modo se potencia la verosimilitud de lo narrado -el lector cree estar presenciando un hecho que ocurre ante sus ojos- y un suspense que lleva al lector a querer saber qué sucede después. Esto se logra a través de la construcción de una trama en la que los datos se dosifican (Hoyos, 2003). Así, en El Ángel Negro, Palacios entremezcla en sus 12 capítulos dos historias: asistimos, por una parte, a una reconstrucción de la vida de Robledo Puch, desde la infancia y sus inicios en el crimen hasta el final del juicio que le llevó a la cárcel; y, por otra parte, atendemos al presente de la investigación y a la relación que comparten reportero y criminal. Surge así un tiempo que se corresponde con las necesidades del relato, un tiempo que es una ficción creada por el narrador: "el tiempo del relato" (Hoyos, 2003).

Otra estrategia narrativa fundamental para que el relato funcione está en el manejo del ritmo. Para ello el cronista dispone de varias opciones. En "Rápido, furioso, muerto", Javier Sinay mezcla dos historias de vida -la de la víctima, Axel Lucero, y la del policía que le asesina, Jorge Caballero- y dos momentos de la historia -la del hecho en sí, en la que se produce la muerte de Axel, y la de sus consecuencias, en la vida de los familiares y amigos de la víctima y del policía Caballero-. Pero, además, Sinay retrata varios fenómenos anexos, como la fascinación de los jóvenes villeros por las motos, el crimen como modo de lograrlas y, fundamentalmente, el uso de armas reglamentarias fuera de servicio por parte de policías que terminan en crimen.

Afirma Hoyos (2003) que el ritmo "nace del empleo diferenciado de dos modos narrativos -la escena y el resumen- y de su combinación con la descripción” (p. 207). Sinay logra la ruptura del ritmo en la narración sirviéndose de resúmenes, en los que profundiza en la legislación respecto al uso de armas por agentes de la ley o las cifras de víctimas por su uso no regulado, entre otros asuntos. Pero, además, en las escenas que forman el grueso de su crónica modifica el tiempo de la historia sirviéndose de la "aceleración" y la "condensación" (Hoyos, 2003). El planteamiento de la historia, en el que se nos presentan los momentos previos al crimen, se prolonga durante seis párrafos que cierran con un párrafo breve: "Ninguno de ellos estaba listo para la balacera. Y el negrito no estaba listo para morir ¿Quién lo está a los 16 años?” (Sinay, 2016, p.112).En cambio, el momento en el que se consuma el crimen se solventa en unas pocas líneas en las que es el propio policía quien lo relata:

Yo le di la espalda porque no quería que me revisara -dice Caballero. -Si buscaba mi billetera y mi celular, quizá me manoteaba el fierro y yo no sabía cómo podía terminar eso. Como yo le digo: ¡Listo, listo, listo! ¡Llévatela!, en un momento el loco se sube y me da la espalda. Y ahí saco yo mi arma y martillo (Sinay, 2016, p. 124).

Gracias a este manejo del tiempo -además del dramatismo que otorga la voz del ejecutor- Sinay logra en la primera parte del relato que el lector esté en tensión a la es- 
pera de que la historia alcance el clímax, mientras que en la escena de la muerte refleja lo inevitable y la precipitación del hecho. En definitiva, su reportaje logra que el lector sea partícipe y testigo de la historia que relata.

\section{Conclusión}

El crimen y el delito son asuntos que la prensa refleja habitualmente; que interesan a los lectores y que requieren ser tratados informativamente por su propia condición de fenómenos perturbadores de la vida en sociedad. Sin embargo, es común en la cobertura mediática de estos hechos la utilización de estrategias periodísticas controvertidas, como la espectacularización, el abuso de adjetivos calificativos y titulares alarmantes o la descontextualización. El crimen y el delito esconden realidades y fenómenos en los que el tratamiento de la prensa masiva, condicionado por la limitación de espacio, la velocidad con la que se suceden los hechos y la obligación de cambiar constantemente de tema debido a las necesidades de la actualidad, no puede profundizar. Los casos suceden, se informa sobre ellos y con el tiempo son sustituidos por nuevos hechos por exigencias de la agenda informativa o nuevas necesidades en el interés del público.

Sin embargo, hay un tipo de periodismo que regresa sobre esos temas y nos permite acceder a nuevos significados de los hechos. Profundiza en las causas y el contexto y nos permite conocer las distintas versiones y los fenómenos relacionados. Lo hace desde la investigación y la narración. El periodista se desplaza a los lugares en los que sucedieron los hechos, consulta la documentación existente y a las fuentes oficiales y expertos que participaron en la investigación o pueden aportar detalles significativos. Pero, sobre todo, escucha a las personas que los vivieron, habla con las víctimas y los testigos y no evita atender también al relato de "los culpables". Gracias a ello podemos conocer el impacto que estos acontecimientos tuvieron es sus vidas y también las distintas realidades y fenómenos que se dan en la sociedad. Este periodismo de investigación y narrativo asume las obligaciones que debería tener el periodismo más convencional, como es el caso del tratamiento de las fuentes, de comprobar sus afirmaciones y verificar los hechos que cuentan. Los datos que se narran deben de ser reales y comprobables. Por otro lado, estas historias buscan, desde la narración, ser atractivas y conectar con el lector, mostrarle estas historias del modo más veraz posible, más auténtico y vivo, sirviéndose de los recursos que la retórica y la poética ponen al alcance del cronista. En este periodismo narrativo el reportero asume una mirada y hace partícipe al lector del proceso periodístico, por lo que transforma la relación entre periodista y lector.

Los trabajos periodísticos de Rodolfo Palacios y Javier Sinay son un buen exponente de este periodismo en la Argentina de hoy. Su mirada y su voz como cronistas es original y comprometida; atractiva como lectura y necesaria como periodismo. Conscientes de que parten de una materia prima -el delito- polémica y que se presta al uso de lo escabro- 
so, el lugar común o la exageración; se imponen unos límites y unos principios éticos que permiten que sus textos cumplan una función mayor a la de la cobertura breve y apresurada de un hecho delictivo en la prensa diaria. Sus relatos profundizan y muestran realidades mayores, exhiben los rincones más ocultos de la sociedad y las facetas más oscuras de sus habitantes; exponen y denuncian. Para lograrlo mezclan curiosidad, trabajo de campo, documentación, compromiso ético y político, y calidad literaria. Son herederos de una tradición de periodismo narrativo en el país en el que el crimen siempre tuvo un papel protagónico. Una tradición en la que se encuentran las primeras crónicas modernistas previas a la aparición de la prensa popular, los reporteros policiales de inicios del siglo XX con Crítica como laboratorio y el compromiso y el ejemplo del periodismo de Rodolfo Walsh. Una suma de influencias e ingredientes que dotan al periodismo policial argentino de gran personalidad y calidad.

\section{Bibliografía}

Abós, A. (2013). Roberto Arlt, cronista del crimen, en Roberto Arlt el facineroso. Crónicas policiales. Buenos Aires: Del Nuevo Extremo.

Adoue, S. B. (2011). Walsh, el criptógrafo. Escritura y acción política en la obra de Rodolfo Walsh. Buenos Aires: Dialektik Editora y Editorial El Colectivo.

Amar Sánchez, A. M. (1992). El relato de los hechos. Rodolfo Walsh: testimonio y escritura. Rosario: Beatriz Viterbo Editora.

Angulo Egea, M. (2012). Bajo la piel de la marginalidad argentina. Crónicas literarias sobre los nuevos sujetos de la violencia. En Rodríguez Rodríguez, J.M. (Coord.) Contar la realidad. El drama como eje del periodismo narrativo (pp. 73-100). Madrid: 451 Editores.

Angulo Egea, M. (2013). Crónicas de Buenos Aires. La megalópolis porteña en el periodismo literario argentino actual. Estudios sobre el Mensaje Periodístico, 19, vol. 2 (julio-diciembre), 615-633. http://dx.doi.org/10.5209/rev_ESMP.2013.v19. $\mathrm{n} 2.43462$

Angulo Egea, M. (Coord.). (2014). Crónica y mirada. Aproximaciones al periodismo narrativo. Madrid: Libros del K.O.

Angulo Egea, M. (2016). El realismo intransigente del periodismo literario de Martín Caparrós. Compromiso político, sentido histórico y voluntad de estilo. Estudios sobre el Mensaje Periodístico, 22 (2), 627-645. http://dx.doi.org/10.5209/ ESMP.54226

Angulo Egea, M. (2017, en prensa). Inmersiones. Crónica de viaje y periodismo encubierto. Barcelona: Colección Periodismo Activo. Universidad de Barcelona.

Bencomo, A. (2007).Violencia crónica o crónica de violencia: José Duque y Rosana Reguillo. En Falbo, G. Tras las huellas de una escritura en tránsito. La crónica contemporánea en 
América Latina (pp. 21-40). La Plata: Ediciones Al Margen.

Brunetti, P. (2008). Sensacionalismo y renovación en la prensa gráfica cordobesa (1897-

1914). En Brunetti, P., Maggio Ramírez, M., Grillo, M. Ensayos sobre la prensa. Primer Concurso de Investigación en Periódicos Argentinos en homenaje al Prof. Jorge B. Rivera (pp. 23-195). Buenos Aires: Ediciones Biblioteca Nacional.

Caminos Marcet, J.M. (1997). Periodismo de investigación. Teoría y práctica. Madrid: Síntesis. Casals Carro, M. J. (2001). La narrativa periodística o la retórica de la realidad construida. Estudios sobre el Mensaje Periodístico, 7, 195-219.

Chiappe, D. (2010). Tan real como la ficción. Herramientas narrativas en periodismo. Barcelona: Editorial Laertes.

Fernández, D. (1999). La violencia de los signos. Sensaciones y carencias de recursos narrativos. Diálogos de la Comunicación, 55, 99-11.

Ferro, R. (2010a). Palabras liminares y criterios de edición. En Walsh, R. Operación Masacre. Seguido de la campaña periodística (pp. 9-13). Buenos Aires: Ediciones La Flor.

Ferro, R. (2010b). Fusilados al amanecer, Rodolfo Walsh y el crimen de Suárez. Buenos Aires: Editorial Biblos.

Genette, G. (2001). Umbrales. México: Siglo XXI.

Herrscher, R. (2012). Periodismo narrativo. Manual para contar la realidad con las armas de la literatura. Barcelona: Colección de Periodismo Activo. Universidad de Barcelona.

Hoyos, J. J. (2003). Escribiendo historias. El arte y el oficio de narrar en el periodismo. Medellín: Editorial Universidad de Antioquía

Lanza, C. (2010). Introducción. En La chica mala del periodismo, Crónica roja en Bolivia (pp. 9-24). La Paz: Fiedrich Ebert Stiftung (FES).

Licitra, J. (2011). Los Otros. Una historia del conurbano bonaerense. Buenos Aires: Editorial Debate.

Lodge, D. (1999). El arte de la ficción. Barcelona: Península.

López Gijsberts, D. y Malharro, M. (1999). El periodismo de denuncia y de investigación en Argentina. De La Gaceta a Operación Masacre (1810-1957). La Plata: Ediciones de Periodismo y Comunicación.

Ornelas Arriaga, J. L. (2002). “Colombianización” o "mexicanización” periodística. La nota roja en los noventa. Razón y palabra, 26. Recuperado de: http://www.razonypalabra.org. $\mathrm{mx} /$ anteriores/n26/jarriaga.html

Palacios, R. (2010). El Ángel negro. Vida de Carlos Robledo Puch, asesino serial. Buenos Aires: Aguilar.

Palacios, R. (2012). Conchita. Ricardo Barreda, el hombre que no amaba a las mujeres Buenos Aires: Libros de Cerca.

Palacios, R. (2012). Adorables criaturas. Crónicas grotescas de ladrones y asesinos. Buenos Aires: Editorial Fundación Ross. 
Palacios, R. (2014). Sin armas ni rencores. El robo al Banco Río contado por sus autores. Buenos Aires: Editorial Planeta.

Palacios, R. (2015). El Clan Puccio. La historia definitiva. Buenos Aires: Editorial Planeta.

Rivera, J. B. (1980). La forja del escritor profesional (1900-1930). Los escritores y los nuevos medios masivos. En Zanetti S. (Ed.) La historia de la literatura argentina. Vol. 57 (pp. 361-384). Buenos Aires: Centro Editor de América Latina.

Rodríguez, P. (1994). Periodismo de investigación: técnicas y estrategias. Barcelona: Ediciones Paidós.

Rodríguez Cárcela, R. (2011). La información de sucesos. Temática en prensa escrita. Correspondencias \& Análisis. 1, 309-325.

Rodríguez Rodríguez, J. M. (Coord.). (2012). Contar la realidad. El drama como eje del periodismo narrativo. Madrid: 451 Editores.

Rojas, D. (2011).¿Quién mató a Mariano Ferreyra? Buenos Aires: Norma.

Rotker, S. (2005). La invención de la crónica. México: Fondo de Cultura Económica.

Saítta, S. (2013). Regueros de tinta. El diario Crítica en la década del 1920. Buenos Aires: Siglo XXI Editores.

Schnirmajer, A. (2010). Prólogo. En Schnirmajer, A. (Ed.). ¡Arriba las manos!" Crónicas de crímenes, "filo misho" y otros cuentos del tío (pp. 13-34). Buenos Aires: Eterna Cadencia.

Sierra Caballero, F. y López Hidalgo, A. (2016). Periodismo narrativo y estética de la recepción. La ruptura del canon y la nueva crónica latinoamericana. Estudios sobre el Mensaje Periodístico, 22 (2), 915-934. http://dx.doi.org/10.5209/ESMP.54243

Sinay, J. (2009). Sangre joven. Matar y morir antes de la adultez. Buenos Aires: Tusquets.

Sinay, J. (2010). 100 crímenes resonantes que conmovieron a la sociedad argentina. Buenos Aires: Editorial Planeta.

Sinay, J. (2013). Los crímenes de Moisés Ville. Una historia de gauchos y judíos. Buenos Aires: Tusquets.

Sinay, J. (2016). Las ratas invaden la escena del cuádruple crimen (y otras crónicas). Ciudad de México: Ayuntamiento de Nezahualcóyotl y Para Leer En Libertad AC.

Walsh, R. (1997). Caso Satanowsky. Buenos Aires: Ediciones De La Flor.

Walsh, R. (1997). ¿Quién mató a Rosendo? Buenos Aires: Ediciones De La Flor.

Walsh, R. (2008). Operación Masacre. Buenos Aires: Ediciones De La Flor. 